Article

\title{
Differentiated Embedding and Social Relationships Among Russian Migrant Physicians in Finland: A Narrative Socio-Analysis
}

\author{
Driss Habti \\ Karelian Institute, University of Eastern Finland, Finland; E-Mail: driss.habti@uef.fi
}

Submitted: 24 May 2021 | Accepted: 28 October 2021 | Published: 15 December 2021

\begin{abstract}
Migrants' processes of (dis)embedding in local and transnational social networks have received growing attention in recent years, but most research focuses on low-skilled migration. This study explores the affordances and challenges that Russian physicians, as a high-skilled migrant group in Finland, experience in these processes in work and non-work domains. Based on semi-structured biographical interviews with 26 Russian physicians, the study employs Bourdieu's socio-analysis to analyze their narratives. The results reveal that Russian migrant physicians negotiate and experience differentiated embedding across work-life domains in local and transnational contexts. They mostly develop collegial relationships with Finnish colleagues and benefit from fulfilling professional relationships in the work domain. However, alongside time and efforts needed for building social ties, various factors often impede friendship making and socialization with locals beyond the work domain. These physicians cope with individual life circumstances through their enduring and supportive relationships with their Russian relatives and colleagues-friends. These results indicate that high-skilled migrants have a greater opportunity to connect professionally with locals than low-skilled migrants, but experience similar challenges to the latter in building close personal relationships.
\end{abstract}

\section{Keywords}

embedding; friendship; Russian migrant physicians; social relationships; socio-analysis; work-life domains

\section{Issue}

This article is part of the issue "In Good Company? Personal Relationships, Network Embeddedness, and Social Inclusion" edited by Miranda J. Lubbers (Autonomous University of Barcelona, Spain).

(C) 2021 by the author; licensee Cogitatio (Lisbon, Portugal). This article is licensed under a Creative Commons Attribution 4.0 International License (CC BY).

\section{Introduction}

High-skilled migration research on social networks, friendship making, and the resources they provide in social integration has burgeoned in the last decade (cf. Ryan, 2011, 2015), although research has focused primarily on social networks of "low-skilled" migrants (Lubbers et al., 2021). Research interest in work-life domains among high-skilled migrants has been embedded in the academic tradition of global economy and labor market integration in such disciplines as human resource development and management, political economy, and human geography (Favell et al., 2007; Habti, 2012, pp. 149-151). Empirical studies across disciplines have provided insights into the employability and career mobility of high-skilled migrants as a fundamental feature of social integration in receiving countries (cf. Habti,
2012; van Riemsdijk \& Wang, 2017). However, beyond professional opportunities in the work environment, transnational mobility, and networking, the "human face" (Favell et al., 2007) of their social lives has been little considered although these latter may be characterized by challenges in socialization and friendship making (Ryan, 2011; Ryan \& Mulholland, 2014). Research in the Nordic countries has shown that high-skilled migrants often experience challenges in social integration related to language, sociocultural norms, and friendship making (Habti, 2014; Povrzanović-Frykman \& Mozetič, 2020), and adjustment to informal social settings, acculturation, and identity negotiation (Habti, 2012, pp. 149-151; Lahti, 2013).

Forming social networks is "the product of endless effort to produce and reproduce lasting, useful relationships that can secure material or symbolic profits" 
(Bourdieu, 1986, p. 90), while social relationships are "conduits for flows of material and non-material resources" (Bilecen \& Lubbers, 2021, p. 838). Building social relationships with local natives require much time, effort, and nurturing, because they are triggered by opportunities, structures, skills, and shared interests (Ryan \& Mulholland, 2014). Research on low-skilled migrants found that social networks were ethnically or racially homogenous in a wide range of relationships, from marriage to work relationships and old-school friendship ties (Ryan, 2011). Nevertheless, research has lately shown interest in high-skilled migrants' social embedding and networking outside the work domain.

Building on a range of theories and concepts on social embedding, migrant networks, and social relationships, this study contributes to existing research by adopting a work-life approach to identify and understand the affordances and challenges Russian migrant physicians experience in apparently diverse and dynamic processes of embedding. Conceptually, "embedding" is used to understand the diversity of migrant's ties as they perform various functions across various social settings (Ryan, 2011, 2015). Moreover, it may carry less normative theoretical baggage than "integration" and "assimilation" theories, which overlooked the dynamics of embeddedness over time (Lubbers et al., 2021). The study draws on qualitative biographical interviews from 26 Russian migrant physicians, and uses Bourdieu's (Bourdieu \& Wacquant, 1992) socio-analysis of narratives and meaning-making at the micro-level. It examines what facilitates and inhibits social embedding, access to and maintenance of social relationships in different work-life domains in the context of Russian migrant physicians.

\section{Migration of Russian Physicians in Finland}

Finland is a small and highly homogeneous society of five million people, with an immigrant community of three percent. The Russian-speaking community is the largest foreign language group in Finland, comprising almost 21 percent (around 79,000 people) of foreign language speakers (Habti, 2019). Most Russian immigrants live in the Helsinki area in the south and in eastern border cities, where their contacts with Russia are maintained through cross-border mobility. They actively participate in creating extensive transnational social ties and networks in both countries (Kemppainen et al., 2021). Generally, they are considered less visible and culturally more proximal to the Finnish population than other ethnic migrant groups. However, studies show they experienced discrimination based on social, political, and historical grounds (Liebkind et al., 2016). Moreover, high-skilled migrants in culturally diverse workplaces face stigma because of their "Russianness" when negotiating their cultural identity (Lahti, 2013).

Russian migrant physicians are the largest group of foreign-born physicians, and their migration has developed through different channels since the 1990s
(Habti, 2019). Their migration can be attributed to the post-Soviet Union crisis and the ensuing deterioration of socio-economic and political conditions. An EU-Russia partnership agreement made in 1997 fueled workrelated migration to Finland. Besides, major EU regulations regarding residence procedures and labor integration transition governed mobility and migration from Russia. Finland has suffered from shortages of physicians, especially in rural and remote areas, and has started to recruit foreign-born physicians. The number of Russian migrant physicians remains small, though it has increased in the last decade from 357 to 644 physicians in 2016, with a large proportion of women, at 60 percent. Habti (2019) found that their motivation and aspiration for migrating are better career expectations, quality of life, and the prospect of permanent stay. Moreover, major drivers for migration for many physicians were work, marriage, and Ingrian Finns' repatriation.

\section{Theoretical Considerations}

Granovetter (1985, p. 490) developed the concept of embeddedness that emphasized the "role of concrete personal relationships and structures" in individual agency, necessitating a continual effort to develop, reform, and maintain them. The convertibility of social networks into actual or virtual resources, accessed or employed in social relationships, equals "social capital" (Bourdieu \& Wacquant, 1992, p. 119). Korinek et al. (2005, p. 780) defined embeddedness as "social relationships that foster a sense of rootedness and integration." They added that:

Embeddedness emerges through a variegated web of social ties, some of which link migrants to kin, covillagers, and others with whom they are familiar and share a common background, and others of which link migrants to new, diverse, urban-based folks who share their new environment. (Korinek et al., 2005, p. 782)

Research into conceptualization of migrants' experience of social networks proposed ways of thinking about nuanced details of migrants' engagement with people and places constituting their relational social world, and which mitigate such fixed concepts as "inclusion" and "exclusion," "integration," and "assimilation." As Lubbers et al. (2021, pp. 529-530) observe, critics of assimilation and integration theories indicated the "methodological nationalism" implied in these theories, which "focus only on that part of the migration experience that falls within the boundaries of the receiving nation states, reproducing state projects" and "ignore the internal heterogeneity of 'ethnic communities' " (see also Wimmer \& Glick Schiller, 2002).

Migrant social networks and relationships may illuminate their dynamic and multi-layered sociability patterns over time in work-life domains. Importantly, 
their study avoids pitfalls of the "ethnicity-centrism" and methodological nationalism of previous research (Dahinden, 2016). Considering the interest in migrants' embeddedness in local and transnational social systems, the concept of "embedding" has been used to understand how migrants' processes of becoming embedded in these systems unfold (Ryan \& Mulholland, 2014, 2015). Embedding is a useful concept for understanding the dynamic process through which migrants build social relationships and attachments, and access resources with specific people across different life domains. Moreover, "differentiated embedding" highlights the characteristics of various levels of attachment and belonging migrants negotiate (Ryan, 2018, p. 237). Ryan's emphasis on such conceptual approach seeks to overcome the "simplistic" and one-dimensional views of migrant integration and networking. It also illuminates migrants' complex experiences of diverse social ties more subtly, moving beyond polarized accounts of success/failure binaries in migrants' integration paradigm.

A similar line of research emphasized processes of social embedding are fundamentally "shaped by factors beyond individuals' agency" (Lubbers et al., 2021, p. 546). Embeddedness may be influenced by other factors such as structural conditions, life events, life stages and socio-demographic factors. To understand the different degrees of embedding, we need to examine the major domains within which embeddedness occurs and the web of social relationships that develops. Korinek et al. (2005) suggest four domains of embeddedness which may overlap: household, workplace, neighborhood, and wider community. Such multi-dimensional aspects of embedding allow identification of various factors and degrees of embeddedness in specific domains (work, nonwork), and different spaces of networking (local, transnational, physical, virtual). Besides, the relational aspects of networks are important for facilitating migrants' embedding. As Hite (2003, p. 13) explains, "relational embeddedness" does not represent "a single, dichotomous construct" within social ties that show if a person is either embedded or not, but "most strong network ties, like most groups of friends, are of sufficient variation to be more precisely classified and differentiated by the specific characteristics of their social relationships." Ryan and Mulholland (2015, p. 141) call for understanding such characteristics by exploring the nature of migrants' social embedding and relationships in particular networks, and their changing needs and priorities through their life courses.

Social networks in the workplace are "conduits of information and resources exchanged by actors in pursuit of instrumental objectives" (Podolny \& Baron, 1997, p. 675), "regulating influence and reputation, providing socialization, mentoring and models for constructing identities" (Ibarra \& Deshpande, 2004, p. 6). Lately, an extensive body of research has addressed the role of the workplace as a source of social relationships, and the influence of networks in the workplace, especially informal relationships (Yakubovich \& Burg, 2019), in facilitating opportunities for professional competence and career progression within and between organizations. Informal coworker relationships are important sources of support and friendship (Morrison \& Cooper-Thomas, 2016). Particularly, work relationships are effective when they include sparse weak ties to enable a flow of information and learning (Blouin, 2018), and strong ties based on loyalty and mutual support (Mikkola et al., 2018). Coworker relationships can, however, turn into "voluntary and holistic" friendships, cherishing positive attitudes, social and emotional support (Morrison \& Cooper-Thomas, 2016, p. 123).

Work and nonwork experiences are generally understood as subjective perceptions of interrelations between the two (Povrzanović-Frykman \& Mozetič, 2020). People need to have shared interests to access and form new interpersonal relationships in social domains of work, family, hobbies, or the residential neighborhood. Beyond work-related "privileges" highskilled migrants may accumulate in the work domain, their social life involves non-instrumental aspects such as socialization for the sake of "real, close friendship" (Ryan, 2011, p. 722). These experiences may foster local activities and close relationships within different social networks. Such relationships may also give access to positive resources for individuals such as interpersonal trust, reciprocity, social support, a sense of belonging, and identity. However, like low-skilled migrants, they may have negative experiences in the local society, such as social and racialized categorization, and failed sociocultural adjustment because of the missing cultural and ethnic proximity with local society (Habti, 2014; Lahti, 2013). Such challenges may emerge with disadvantageous outcomes in culturally diverse workplaces (cf. Habti, 2012, pp. 149-151; van Riemsdijk et al., 2016), even when high-skilled migrants are assumed to fare well in professional life.

Because friendships are usually viewed as dyadic interpersonal relationships, their social significance may be overlooked. Social relationships such as friendships do not simply represent relations between two people; they connect overlapping networks of relations between different people, usually through shared interests and experiences in particular temporal and spatial contexts (Ryan, 2015). Furthermore, migrants' exchange of support with co-ethnics and co-nationals in local society (Ryan, 2011) signals their importance in the adjustment to that society. Many studies indicated that such networks tend to support migrants with opportunities by providing important resources to their members (Ryan \& Mulholland, 2015). In exploring the characteristic composition of relationships, we may understand whether and why migrants experience transversal social embedding and ties that may intersect, for example, with ethnicnational backgrounds, within local and transnational spaces of interactions. However, shared interests and opportunity structures are sources of friendship making 
and networking, which challenge the simplistic assumption of sought out national and ethnic "enclaves" (Ryan \& Mulholland, 2014).

Moreover, interpersonal relationships can be lasting or fleeting in the space of flows. Networking in such contexts necessitates time, efforts, specific interpersonal skills, self-confidence, and language skills from highskilled migrants. They may draw on high levels of these sources to build a range of social ties in the receiving society (Ryan \& Mulholland, 2015). Additionally, age-related social relationships, networking formation and maintenance, and the effects of career stages on such ties are important to consider (Wrzus et al., 2013) because they influence the meanings and importance of ties. To illustrate, intermarriage can be a resource of integration and broad social ties for female migrant spouses in work-life domains (Jääskeläinen, 2003); otherwise, it may instill loneliness for them (Koelet \& de Valk, 2016).

Migrants are often embedded in and negotiate longdistance ties of different forms of transnational relationships across countries (Bilecen \& Lubbers, 2021). Among their transnational experiences and practices are relationships between family members living in the sending and receiving countries, as an existential form of familyhood over time and space (Baldassar \& Merla, 2014). These ties provide resources in the form of "social remittances" such as ideas, savoir-faire, and social capital (Levitt, 2001), and emotional and care support (Kemppainen et al., 2021) generated through internet-based communication and co-presence. Dahinden (2009) observes that transnational ties and practices include reciprocity between individuals, groups, and communities, solidarity among ethnic groups, trust, and cooperation behind these relational connections. However, research shows human activity remains embedded in geographical locations and social structures (Wimmer \& Glick Schiller, 2002, p. 236), accentuating local and in-person embedding and networking. While ICTs enable online communication, co-presence remains important for forming and maintaining social relationships in different life domains. Moreover, beyond family ties, friendship remains "the best quality in our personal relationships" (Pahl, 2000, p. 43) not only for meetings and communication, but in providing intersubjective spaces for personal and emotional support.

Migrants' diverse experiences of embedding and social relationships need to be seen as a multi-level process of managing work and nonwork domains, as Ryan (2018) highlighted, across different layers or sectors of society. Conceptualizing embeddedness as multi-layered can explain the migrant's experience of social embedding and relationships, and the determinants of their processes. This approach may explain the ways Russian migrant physicians' ties are formed, the social structures and locations in which they unfold, and reasons why they are embedded in some domains and disembedded in others. Building on the theoretical discussion, the empir- ical originality surrounds analysis of the affordances and challenges this high-skilled migrant group experiences in their social embedding.

\section{Data and Methods}

This article presents findings from semi-structured narrative interviews with 26 Russian migrant physicians, conducted in various Finnish cities between 2014 and 2015. It is part of a research project on their career mobility that seeks to capture their perceptions and lived experiences, including social integration in work and nonwork settings. Russian migrant physicians constitute the second-largest foreign-born group after the Swedish (Habti, 2019). The majority of respondents were recruited using a purposive sampling strategy based on the information retrieved from the Finnish Medical Association on registered physicians in Finland. The sample was completed with snowball sampling, by asking the first group of respondents to name other candidates to participate. The sample is unevenly split between 22 females and four males, which is partly due to the higher presence of female Russian physicians in Finland (Habti, 2019). They migrated to Finland between the late 1980 s and 2000s in their early or mid-career stages, which reflects the major trend of their migration to Finland. On average, they had lived in Finland for more than 15 years and worked for around 14 years. Their length of residence ranged between eight and 35 years, providing diverse migration trajectories and experiences. Many held dual citizenship, were married to Finnish citizens, and had children (see Supplementary File).

The interviews were conducted mostly on Skype or in phone calls, while a few were held face-to-face. Most interviewees had difficulty finding convenient time for their interview. The interviews were conducted mostly in Finnish and Russian in accordance with interviewees' preference and lasted between one and a half to two hours. A comprehensive content analysis of the transcripts was performed and coded manually, and the coding was undertaken within and across the transcripts to capture the characteristics of individual narratives and extract the themes shared by interviewees. The transcripts provided rich data, including the interviewees' views of their social networks and relationships in work-life domains. The cited quotations were translated from Russian or Finnish to English. For reasons of confidentiality, personal information such as real names, professional specialization, and locations are undisclosed, and names are pseudonymized. The narrative analysis was guided by grounded theory and draws on Bourdieu's socio-analysis. In his interpretative methodology, the units of analysis are the relational dynamics between actors, contexts, and structures (Bourdieu \& Wacquant, 1992, p. 63). Finding a "logic" in these units' mutual constitution, socio-analysis can reveal the interviewees' self-interpretations in biographies, strategies, practices, and the structures governing their life courses. 
The methodological approach is useful in exploring interviewees' narration of experiences and reflections, capturing insights into the complexity, diversity, and intensity of social relationships in which migrants are embedded within specific networks in work-life domains. Especially relevant are the major determinants and content of migrants' social relationship formations, and the meaning of their (dis)embedding. The analysis section shows the transversally emerging themes in the interview data among the interviewees. It is organized in three subsections, based on forms of social relationships and embeddedness discussed in the theoretical literature: the local work domain, the local life domain, and transnational work-life domains. Each subsection is split into themes characterizing respondents' experiential perceptions of (dis)embedding and social relationships in work and nonwork, local and transnational settings. The themes are not interpreted as separate but as interconnected aspects of general patterns. The concluding section discusses the findings and outlines the study's main contribution and its relevance to the research area of high-skilled migration.

\section{Findings}

\subsection{Embedding in Work Domain}

The interviewees' narratives support recent empirical research that the workplace is not an opportunity structure for close social ties and friendships between migrant professionals and local colleagues, but only for formation and maintenance of "friendly" professional relationships, as previous studies found (Habti, 2014; Povrzanović-Frykman \& Mozetič, 2020). Professional networking is "as much performed on the ground of the corporate world as at the top" (Wittel, 2001, p. 56). As an "opportunistic" resource (Ryan, 2011), such relationships are elemental in boosting professional development, competence, and job opportunities. However, strengthening professional relationships is often part of the job of collegial coworkers. For example, Vladimir, a late career specialist in his 50s, described his relationship with local colleagues as "neutral" and characterized by "mutual respect according to the principle of collegiality." As Ryan (2011) indicates, the value of relationships partly depends on the willingness to share information and know-how. The interviewees emphasized the interprofessional exchange basis with local colleagues on the acquisition of information, skills, and experience in their relationships, especially in their initial career-stage after migration.

Several interviewees had opportunities to develop "good" relations with Finnish peers, and often alluded to the benefits of getting support from Finnish managers (Mikkola et al., 2018). For example, Tatjana, a late career GP aged 55, referred to the role of managers as trustworthy personal contacts in consulting and supporting her: "I always get help, advice and consultation from
managers....I got so much help and support from my senior physician and I knew I could trust her." On the occasions of organizational and professional events such as trainings, these conduits of information and advice are important as they allow interprofessional encounters and learning. However, most interviewees reiterated the fact that interprofessional relationships were fundamentally work-related only, and served as an important career resource especially for younger physicians, depending on employee turnover, as Irina, an earlycareer GP aged 36, explained:

If you encounter mobility between different medical centers, employee turnover doesn't matter. You do your work, communicate with colleagues in the canteen, discuss the weather forecast and travel plans. What matters is probably the motivation to learn more and acquire experience for specialization. But if you work in a department with a low employee turnover for a longer time, this has a big impact, because much depends on how colleagues perceive you, and how you position yourself among them in your relationships.

Irina's conditions of rewarding professional relationships spanning long-term work togetherness are rich sources of learning and experience, but also building propitious interpersonal relations. Hence, long-term work relations may transform professional ties to personal ones, particularly among younger respondents. However, many interviewees highlighted the professional nature of their embedding in the workplace, their interpersonal relationships with colleagues remained "neutral" and "shallow," and restricted within use of and communication through their workplace's intranet. Such infrastructures reduce face-to-face physical meetings and interconnectivity across organizations, which may impede the transformation of interprofessional relationships into close friendships. For example, Olga, a late career GP aged 55, described her "neutral" contact with Finnish colleagues, because they often moved, and she spends most working time in her office: "I work in my office where I consult patients. I participate in meetings along colleagues when our manager gives reports.... have neutral relationships with staff because they change frequently."

Qualifying relationships as "neutral" reinforces the relatively separate distinctiveness between relationships in work and nonwork domains, between "friendly" work relations and voluntary personal friendships (Morrison \& Cooper-Thomas, 2016). Katarina, a late career specialist aged 54, mentioned: "I rarely meet colleagues at work in the coffee room. I don't generally consider colleagues as important as the team I work with." Tania, an early career GP aged 33, differentiates between relationships in work and nonwork life domains, when she remarked: "Work relationship should always be work-related. We come to the hospital to work, not to make friends." This tenet 
resonates with the position on coworker relationship in the Finnish culture that differentiates between work and nonwork personal relationships, though they may be characterized by personal companionship (Mikkola et al., 2018).

People are more likely to help and support each other if there is a strong bond of trust and loyalty between them. Such bonds in coworker relations can turn into voluntary reciprocal friendships (Morrison \& Cooper-Thomas, 2016). Few interviewees experienced this transformation into close friendship with Finnish colleagues. Ksenia, a divorced mid-careerist aged 42 , is a rare case whose small network of normal friends consists mainly of Finnish colleagues, as she mentioned: "There aren't many friends, but we have good relations....It's not such special friendship[s] at work. My social network is more work-related." The characteristic of normality here infers the absence of close ties. Katarina, living and working in a peripheral town, has solely Finnish friends, but she confessed: "I hoped for more friends from my origin [country], but it hasn't happened. I lived twenty years in a quiet provincial place where there are few Russians." Being married with a Finn might have shaped her social embedding within local Finnish contacts-friends. Nevertheless, there are few cases that sustained close ties between Russian and Finnish coworkers within the work domain.

Most interviewees developed friendships with conational Russian colleagues at work. To illustrate, Anastasia, a mid-career specialist aged 43, developed intimate friendship with her former colleague from Russia Olga who supported her when she moved to Finland for work: "We worked together many years in the same medical institution in Russia. We both have friends-colleagues who moved to Finland before us." Olga provided Anastasia with instrumental support sharing important procedural information with her. They somehow transformed their weak tie, a dyadic relationship of professional and interpersonal interests into friendship. Anastasia and Olga developed close friendship based on loyalty and mutual support, and efforts and time given for such relationships. Their close relationships can be explained by their former ties in Russia before migrating to Finland.

\subsection{Embedding in Nonwork Domains}

Migrants' coethnic ties are often assumed to be nurtured by emotional support, reciprocity, and trust (Ryan, 2011). The narratives generally reveal that most interviewees formed friendships and networks with Russian migrants in work and nonwork domains. As high-skilled professionals with a busy workload, an important aspect raised among interviewees is the time and effort needed to build meaningful friendships. The interviewees referred to occasional gatherings, virtual communication, and phone calls as forms of socialization. Maria, an early career specialist aged 31, stated: "Work takes a lot of time. There are many Russian doctors with whom I meet and talk in leisure time. We call each other and sometimes meet." Ksenia interacts with friends "more on the internet, because we all have our own lives and jobs. We don't always have the energy or time to go out together, but almost every weekend we do something, going to the theatre, bowling, or walking." Spatial distancing in her Finnish provincial town reduced Anastasia's socialization with friends: "I can't say I interact intensively with friends. We live in different towns and usually call each other once a week."

Many interviewees discussed the challenges confronted in building close ties outside work, despite frequent professional meeting opportunities. Generally, they confessed becoming close friends with Russian community members. Ivan, a late career specialist aged 52, observed: "I prefer to interact with Russians. I don't have meetings with colleagues outside work. I don't have common interests." Apparently, the narratives reveal their easiness to meet other Russians, because they shared common interests in friendships, a similar culture, language, and roots. As Kennedy (2005, p. 188) argues, strong bonds of friendship, defined by "reciprocity and closeness," can be strengthened by the interviewees' shared transnational experiences. Their migration experiences provided a common motivation for friendship making among these migrants which extended to their families. Additionally, Julia, an early career specialist aged 31, referred to the language barrier: "I have more friends from our Russian culture than work....Finnish language was a challenge at first... and was very stressful." Katarina highlighted her lack of emotional support from friends in her life in a provincial town: "I don't have female Russianspeaking friends, and it actually affects me." Slava, a mid-career specialist aged 40, acknowledged her limited interaction with Finns because of cultural and language differences, and the perceived lack of openness of Finns to foreigners:

I interact mostly with Russian friends. I have good relations with some neighbors. We meet sometimes in the yard and chat. But I couldn't say I interact much with Finns, or have Finnish friends....It's a problem because people aren't open to interaction, especially those who live in the north. I can understand them, because it's very difficult to accept someone from a different culture with a poor command of Finnish.

Most interviewees did not refer to their residential neighbors probably because the neighborhood was not one of their meeting opportunities. Finnish neighbors may be reluctant to build new friendships with migrants because they already have established local ties (Ryan \& Mulholland, 2014). Moreover, immigrants in northern Finland experience limited acceptance among Finnish society (Yeasmin, 2012). For Slava, the northern periphery as a spatiality of socialization may challenge friendship making with locals. The extent to which social 
networks give access to social support depends on migrants' positions in the spatial and temporal context (Ryan \& Mulholland, 2015).

As Lubbers et al. (2021, p. 546) found, building social relationships with locals depends partly on "the cohesiveness of the primary networks of local migrants and natives in the place, and their intersection with factors such as race, gender and social class." Under similar structural conditions, some interviewees succeeded in making Finnish friends outside work mostly because of intermarriage, while others failed, and instead, their social ties and friends largely consisted of Russians. Though ethnic embeddedness and ties may not negatively influence their professional lives and careers, they may result in such "cumulative disadvantage" of social disembeddedness with locals. Such conditions may create social life challenges in adapting to the local sociocultural environment, which several interviewees highlighted in their narratives. Inga, a late career specialist aged 55, admitted: "The difficulty was adaptation to a new country, a new mentality, the loss of connections with close friends." From a transnational perspective, Inga's difficulty in adaptation and embeddedness in the new social life relates to the loss of friends in Russia after migration. Her migration trajectory drastically changed her personal needs, resources, and participation in the new social life. Additionally, few interviewees referred to a "shared sense of relative exclusion" (Kennedy, 2005, p. 190), which results in large bonding ethnic networks negotiated through constructed features of sameness or difference. A few interviewees, like Irina, referred to perceived suspicious attitude and fear towards Russians and Russia, generally labelled as "Russophobia" (Vihavainen, 2013), which they believed to impede social relationships:

It could be said there is Russophobia. It's not nice, but you gradually get used to it. It doesn't hurt....I don't pay attention to it, but this is a disadvantage, I mean interactions with patients and colleagues. It's a feeling; it happens sometimes... and could be expressed openly.

The few interviewees did not narrate how these experiences impede social embedding and networking in local context because the process is driven by factors beyond their individual agency. For Irina, a divorced woman in her early postmigration phase and career stage, the reason of feeling ethnically categorized could be a sense of frustration and disappointment at such life stage in experiencing difficulties to access local ties in informal settings she perceived socio-culturally different. However, Anatoli, an early career specialist aged 35, enjoyed socialization and friendships with some Finns across work-life domains: "Finns are nice and open. I've never experienced any racism....There are people who are cautious toward foreigners. It's easy to break barriers with Finns when you speak Finnish and understand the Finnish way of life." He emphasized the importance of language pro- ficiency and local culture proximity for embedding into social life. His young age and career stage seem instrumental in networking and friendship making. A few others succeeded in building diverse ties in diverse socialization contexts. Alexei, another early career specialist aged 28 , sought friendship and socialization with Finnish colleagues for cultural and language learning and embedding into Finnish cultural life: "Because I work in Finland, I have to learn Finnish, its traditions and things I can learn from Finnish people, not Russians." His stance points to professional and cultural identity aspects of embedding through self-identification with the local sociocultural environment.

Some literature suggests Ingrian-Finnish Russians defined their belonging and "Finnishness" with hybrid identity markers (Varjonen et al., 2013). Few interviewees raised such question when discussing their social networking and embeddedness. Marina, a late career specialist aged 59, has an Ingrian lineage, selfidentified herself as Russian and Finnish: "Finland was a closed country for so long. Few foreigners came, and they haven't been welcome; but I have Finnish roots....In Russia, I always heard I was Finnish, and when I moved here, I was Russian." In navigating her belonging, she expressed such hybrid cultural, ethnic, and national identity. These layered identities could indicate attachment to local society alongside Russian identification. After a long migration life stage in Finland, she conceded her being perceived differently in different national and social settings, which negatively affected her embedding into local social settings. Embedding is highly subjective in nature in any life domain, and the sense of belonging and attachment are important in negotiating it (Ryan, 2018, pp. 246-247).

The interviews revealed rare experiences of "ambiguous embedding" (Ryan, 2018) of interviewees' social life of loneliness and isolation, despite their established working lives. They linked their quality of life to fulfilling social relationships and social life. Elena, a specialist aged 39, confessed: "The quality of life is deficient if a person is lonely. It's difficult to be a single parent." Her divorce and singlehood are major life events that exacerbated her social life and socialization: "I'm lonely and don't have a family; my relatives live in Russia. My work consumes all my time, and I spend nearly all my free time with my child." Though married, Irina felt bereft of her Russian family support network, which negatively affected her wellbeing: "My personal and family experience in Finland has disadvantages, mainly loneliness. My relatives live in Russia. Social life, I mean inward peace and wellbeing, is an advantage and important for me." Alla, a mid-career GP aged 47, saw her missed affinity with Russian language as important in her social life, because she did not use it: "My social life is very poor. This isn't anything ethnic, but it's certainly nicer to speak your mother tongue." Being unusual for professionals with families and children, social life conditions of Elena and Alla appeared devoid of socialization, friendships, 
or pastimes. These interviewees lack time and meeting opportunities to build meaningful friendships with Russians or Finns. Moreover, Russian language is a major cultural and identity marker for Russian migrants which connects them. As such, their migration life courses and marital situations explain their shifting life conditions in Finland.

Few interviewees spoke of successfully transforming coworker relationships into voluntary friendships in nonwork domains. Extant research found that migrants' social relationships are not grounded just on shared ethnic ties (Ryan, 2011). Ljudmila, a mid-career stage GP aged 47, developed friendships through shared meeting contexts of work and hobbies: "Ethnic background doesn't affect my attitude toward other people. It doesn't make any difference where I work.... I made friends through work and hobbies, which are opportunities to get to know people." Her working life, occasional sports, and leisure events for socialization expanded her social ties across her professional circle and beyond. Friendship as a voluntary relationship fulfills enjoyment and satisfaction (Morrison \& Cooper-Thomas, 2016). However, most interviewees did not reveal how they qualify and define "friendship" in such contexts. Vladimir mentioned: "My social network involves work-related leisure time, maybe medical personnel parties, or dinner in a colleague's home." Such occasional informal meetings related to work do not necessarily build close friendships with Finnish colleagues or Finns outside work. Occasional gatherings for lunch in restaurants, or dinner in Finnish colleagues' homes do not necessarily infer dyadic friendship which is reflected in longevity and strength.

Rare cases of friendships with Finns were facilitated by shared opportunities, interests and experiences usually linked to specific places and group activities. Some interviewees formed friendships through their marriage, their spouse's relatives and friends, or their children's schooling and leisure time activities in sports clubs. Sociality with their Finnish partners' relatives and friends offered opportunities to engage in and form relationships with locals. Some interviewees referred to their extended network on their Finnish husband's side, involving relatives and friends. Natalia, a mid-career specialist aged 46, mentioned: "My spouse's old friends and schoolmates have gradually become my friends. When we came to Helsinki, we got to know a few new friends who weren't from work." Her relational embeddedness appeared to develop her sense of connectedness and belonging to local society when attending Finnish social events.

Moreover, interviewees' sports clubs or other group activities may enable locally embedded friendships. For example, Ljudmila had Finnish friends from sport: "The coach at the swimming pool is my friend," and "there's a separate group from ice-swimming that I meet every Tuesday at my place." Anatoli spoke of his friends in his local tennis club: "No Russians play tennis at the club.... have Finnish friends from hobbies and work. They aren't necessarily doctors." Family needs and social connections may foster opportunities for mothers to make friendships outside work. Some interviewees' children also bridged friendship making with Finns. Milla formed a close friendship with her Finnish colleague, partly because they both had "children of the same age in the same school....If there's a need, we help each other in everyday life, not just as duty." She added: "My child attends gymnastics classes, and the coach who works there is also our friend." The structural location of Milla and her friend at work and their children in one school, as meeting opportunities, facilitated their friendship making, while their activities are sources of embedding structured by gender and motherhood role.

\subsection{Transnational Embedding}

Face-to-face and online communication are the most common forms of networking and often reinforce each other. Whereas high-skilled migrants often engage in transnational professional networking, most interviewees did not participate in or maintain official professional ties with Russia. Like most interviewees, Elena admitted: "I'm not involved in professional activities with Russia. I only talk with former colleagues sometimes about subjects unrelated to medicine.... have a network of physicians here I'm familiar with and consult." Elena referred to her professional Finnish ties, and underlined the lack of time, energy, and shared interests reinforced her professional "disembedding" with Russia: "I personally lack the time and energy for professional networking with Russia. Everything is done in its own way in Russia." Moreover, life events such as Elena's divorce and single motherhood might have weakened her transnational connections with Russia. Several interviewees mentioned that structural conditions explained their transnational disembedding. They claimed existing differences between the healthcare systems, education, and profession between Russia and Finland, as Anastasia confessed: “I don't communicate with doctors in Russia about my profession, because they have different spheres and treatment methods."

Nevertheless, some interviewees refereed to maintaining informal personal contact with Russian physicians, as Anastasia reported: "There are doctors who are friends, with whom we talk sometimes on the phone; but we never discuss our work." Others often keep transnational ties with physician acquaintances in Russia and exchanged information with them about professional activities, using communication technologies, namely Facebook, Vkontakte, Skype, or phone calls. Milla noted: "I'm in contact with colleagues through Facebook or Vkontakte about anesthesia for childbirth or some other problems. We just share our personal work experience." Similarly, Ivan maintains professional exchange with his former colleagues-friends in his specialization: "I sometimes chat with anesthesiologists on 
Skype, sharing news about the field." Hence, informal discussions constituted the core of transnational professional ties, while their substantial and meaningful networks are in Finland, because interviewees are deeply embedded in local work context.

Transnational professional ties play an important role for physicians in Russia. Migrant physicians provide transnational health therapy practices, based on trust, a shared language, and belonging to Russia (Kemppainen et al., 2021). A few interviewees exercised transnational medical care practice by transferring their savoir-faire (Levitt, 2001) to former colleagues, friends, or relatives in Russia, such as Inga: "I transmitted the experience I received here to my former colleagues, and they adopted it." Transnational therapy networking consisted of sharing health information, advice, and medications. Tania networked with "a few professionals and acquaintances. Most often, it involves medical prescription when people do not trust Russian drugs." Similarly, Marina recalled the questions she was often asked: "Many ask how to get treatment in Finland. I send them information about doctors and tell them what to do." She also provided her friend with advice and treatment: "My friend's daughter has breast cancer, and they ask me for advice. I write them prescriptions from Finland to buy medicines here." Such care practices extended transnational networking function into medical, social, and emotional support to relatives and acquaintances.

The findings support that multiple connections at the family level are bound by practical and emotional caring. Many interviewees attempted to maintain enduring transnational family ties in Russia. For many interviewees, migrating to neighboring Finland was meant to preserve close connections with families within proximity to Russian Karelia and St. Petersburg. For Slava, "the short distance from my native town makes it possible to visit parents and relatives." Her marriage with a Russian presumably also bridged local and transnational embeddedness and frequent border-crossing trips. Many used phone and social media platforms to maintain ties with families in Russia, as Ksenia noted: "We communicate via internet and often talk on the phone if we don't visit each other." They frequently exchanged visits with relatives as a transnational kinship pattern, as Elena illustrated: "My native home is nearby in Karelia, where my relatives still live....My parents often visit us here." The nature of these transnational relationships frequently involves aspects of caring and emotional support. Life events like marriage, and frequent visits reinforce their kinship ties.

Research pointed to the endurance of migrants' friendship networks back home (Conradson \& Latham, 2005). However, the narratives indicated transnational friendships might weaken with less frequent contact. This suggests less effort was made to maintain friendships with former colleagues or friends in Russia. Anatoli revealed that his close friends were mostly in Finland, but he maintained contact with Russian school friends: "I'm in touch with my friends from the same school... but
I can't say they are close friends." His "old friends" were no longer close, reflecting the changing dispersed friendships he maintained in Finland and Russia. His young age, changing life after migration, and marital life emplaced him in local work-life embeddedness, which shifted his priorities in friendship making.

Several interviewees had less in common with or interest in sustaining relationships with old friends, which are explained by their changed lives and priorities. Vladimir mentioned: "I meet familiar people whom I knew from St. Petersburg University, but I rarely interact with friends - probably one or two calls a year." Perhaps, absence of shared interests or life experiences widened the distance with his old friends, and contact became less frequent over time, considering his late career stage. However, a noteworthy pattern in some narratives was the conception of "friendship" rooted in childhood, schools, university days, or former workplaces, shared links from the past that preserved an emotional attachment based on reminiscence. Alexei admitted: "I left many friends and acquaintances in Russia.....Everyone needs some support. Emotionally, it was quite harsh and the greatest difficulty." Likewise, Anatoli said: "I guess you always get your best friends at school or during childhood." The meaningfulness of friendship has driven the young Alexei and Anatoli to describe old friends as their best friends.

\section{Conclusion}

Existing research has focused on low-skilled migrants' social networks and embeddedness in receiving societies. This study explores the affordances and challenges in processes of social (dis)embedding and friendship making that Russian migrant physicians, as a highskilled group, experienced in Finland. The study analyzed how they form and mobilize different ties as resource or support in work-life domains in local and transnational contexts. Earlier, Ryan and Mulholland (2014) found that building meaningful friendships for high-skilled migrants requires nurturing, efforts and time. The study approaches social embedding as dynamic over time, depending on changing social and individual life circumstances (Ryan, 2011, 2015). Drawing upon Bourdieu's narrative socio-analysis, the migrants' experiences on how they navigate work-life domains in terms of social (dis)embedding were motivated by various relational and structural conditions and, sometimes, individual agency, which fostered forms of 'differentiated' social embeddedness and ties across life domains.

The results confirm that these high-skilled migrants found difficulties in translating coworker relationships into close ties and friendships with Finnish colleagues. They based their work relationships on existing shared professional opportunities and interests that serve professional practice and career progression. Social relationships with Finnish colleagues are mostly interprofessional within a web of professional ties. The workplace 
does not constitute meeting opportunity structures for nurturing and building close ties and friendships with Finnish colleagues, considering the changing needs and priorities in career phases. Few cases, however, showed voluntary reciprocal friendships, driven by individual agency rather than structural contexts of the workplace. Relational dynamics of embedding such as intermarriage, or spatial dynamics of peripheral locality also nurture such ties. The important finding, however, is the prevalent pattern of social ties with Russian colleagues, combining weak and strong ties, which provide supportive friendships in nonwork domain.

The findings show that Russian physicians generally succeeded to form close ties with Russian colleagues outside work and across larger Russian community. Common interests in friendships, similar culture, language, and roots create strong friendship defined by "reciprocity and closeness" (Kennedy, 2005). Their migration experiences as major life events provided a common motivation for friendship making which often extended to their families, while culturally sensitive and emotional support nurture coethnic ties (Ryan, 2011). Hence, social embedding and networking within the Russian community appear to be structured around ethnic solidarity, identity, and affiliation. Agency played a role because some made no attempt to establish close ties with locals. Additionally, socio-cultural adaptation and openness were perceived as challenges to socialization and friendship building with locals. Yet, a pattern that transcended such "boundaries" and allowed friendship building with Finns challenges the simplistic assumption of embedding into national-ethnic "enclaves." Relational ties with Finnish spouses' relatives and friends facilitated Russian physicians to extend local networks. However, relationships to the spouse's kin and friends do not necessarily increase belonging. A few women who were married to Finns reported loneliness and isolation in social life, while disadvantageous life events of divorce and singlehood exacerbated such experiences for others.

Transnationally, the findings revealed an absence of professional ties with Russia at the institutional level. However, there were informal dyadic ties with former colleagues and old friends, exchanging information and experience. Nevertheless, as high-skilled professionals, they sometimes transfer their savoir-faire as social remittances (Levitt, 2001), such as medical practice, advice, and prescriptions. They maintain close and mutually supportive transnational ties with families in Russia. Life events like marriage and frequent exchange of visits between families living close to the border reinforce transnational kinship ties. Yet, dyadic ties with old friends become weak. Changing life circumstances and interests after migration seem to shift their priorities, and widen the distance with them, as they become more embedded in local work-life domains (also Lubbers et al., 2021). However, their conception of friendship is rooted in childhood, former schools or universities, or former work- place in Russia. Interestingly, in the local context, friendship is clearly delineated with such emotional attachment based on reminiscence of the past.

In sum, the findings disclose a heterogeneity of individual migration experiences despite the clear characteristic patterns of the migrants' social embedding. Russian migrant physicians in Finland experience intersecting yet differentiated embedding across work-life domains. They appear well-integrated in the work domain but have less close social relationships with locals whether work or nonwork related. In this regard, their social embedding resembled that of high-skilled Arab women in Finland (Habti, 2014) and migrant physicians of various origins in Sweden (Povrzanović-Frykman \& Mozetič, 2020); however, it differed from French high-skilled migrants in the UK who showed greater ease in forming friendships with work peers (Ryan \& Mulholland, 2014). The degree of autonomy in the job and the local culture explains some of these similarities and differences. They seem generally disembedded from the local community in their social lives, and even more in their engagement with Russia, as high-skilled diaspora members, to harness and transfer their skills and experiences at a national level. This study contributes to the discussion on social embedding and networks among high-skilled migrant groups, and their experienced opportunities and challenges in the processes. Further research is needed to approach social embedding using narrative analysis and qualitative life course approach, because migrants' experiences are multi-layered, idiosyncratic, and operate across different life domains.

\section{Acknowledgments}

The author would like to thank the academic editor of the thematic issue and the two anonymous referees for providing helpful comments for revision. Grateful acknowledgment goes to Kone Foundation for funding this study as part of a research project (2014-2016). Last, thanks go to Karelian Institute for supporting the publication of this article.

\section{Conflict of Interests}

The author declares no conflict of interests.

\section{Supplementary Material}

Supplementary material for this article is available online in the format provided by the author (unedited).

\section{References}

Baldassar, L., \& Merla, L. (2014). Transnational families, migration and the circulation of care: Understanding mobility and absence in family life. Routledge.

Bilecen, B., \& Lubbers, M. J. (2021). The networked character of migration and transnationalism. Global Net- 
works, 21(4), 837-852. https://doi.org/10.1111/glob. 12317

Blouin, D. (2018). Impact of interpersonal relations on learning and development of professional identity: A study of residents' perceptions. Emergency Medicine Australasia, 30(3), 398-405.

Bourdieu, P. (1986). The forms of capital. In J. Richardson (Ed.), Handbook of theory and research for the sociology of education (pp. 241-258). Greenwood.

Bourdieu, P., \& Wacquant, L. J. D. (1992). Sociology as socio-analysis. In An invitation to reflexive sociology (pp. 62-74). University of Chicago Press.

Conradson, D., \& Latham, A. (2005). Friendship, transnationality in a world city: Antipodean transmigrants in London. Journal of Ethnic and Migration Studies, 31(2), 287-305. https://doi.org/10.1080/1369 183042000339936

Dahinden, J. (2009). Are we all transnationals now? Network transnationalism and transnational subjectivity: The differing impacts of globalization on the inhabitants of a small Swiss city. Ethnic and Racial Studies, 32(8), 1365-1386. https://doi.org/10.1080/ 01419870802506534

Dahinden, J. (2016). A plea for the "de-migranticization" of research on migration and integration. Ethnic and Racial Studies, 39(13), 2207-2225. https://doi.org/ 10.1080/01419870.2015.1124129

Favell, A., Feldblum, M., \& Smith, M. P. (2007). The human face of global mobility: A research agenda. Society, 44(2), 15-25. https://doi.org/10.1007/BF 02819922

Granovetter, M. (1985). Economic action and social structure: The problem of embeddedness. American Journal of Sociology, 91(3), 481-510.

Habti, D. (2012). Highly skilled mobility and migration from MENA region to Finland: A socio-analytical approach [PhD dissertation, University of Eastern Finland]. UEF eRepo. http://urn.fi/URN:ISBN:978-95261-0863-6

Habti, D. (2014). Spatialities of work and home in dualcareer context of highly skilled Arab women in Finland. Journal of Finnish Studies, 17(1/2), 92-125.

Habti, D. (2019). What's driving migrant Russian physicians to stay permanently in Finland? A life-course approach. Journal of Finnish Studies, 22(1/2), 85-118.

Hite, J. (2003). Patterns of multidimensionality among embedded network ties: A typology of relational embeddedness in emerging entrepreneurial firms. Strategic Organization, 1(1), 9-49. https://doi.org/ $10.1177 / 147612700311002$

Ibarra, H., \& Deshpande, P. (2004). Networks and identities: Reciprocal influences on career processes and outcomes. (Working Paper 2004/85/OB). INSEAD. https://flora.insead.edu/fichiersti_wp/inseadwp 2004/2004-85.pdf

Jääskeläinen, A. (2003). Intermarriage and segmented integration into Finnish society: Immigrant women from the former Soviet Union. Finnish Yearbook of Population Research, 39, 33-54. https://doi.org/ 10.23979/fypr.44983

Kemppainen, L., Shpakovskaya, L., Perheentupa, I., \& Habti, D. (2021). Giving and receiving help across the border: Transnational health practices of migrants in Finland. In C. Vindrola-Padros (Ed.), Care work and medical travel: Exploring the emotional dimensions of caring on the move (pp. 115-140). Lexington Books.

Kennedy, P. (2005). Joining, constructing and benefiting from the global workplace. The Sociological Review, 53(1), 172-197. https://doi.org/10.1111/ j.1467-954X.2005.00508.x

Koelet, S., \& de Valk, H. A. (2016). Social networks and feelings of social loneliness after migration: The case of European migrants with a native partner in Belgium. Ethnicities, 16(4), 610-630. https://doi.org/ $10.1177 / 1468796816638398$

Korinek, K., Entwisle, B., \& Jampaklay, A. (2005). Through thick and thin: Layers of social ties and urban settlement among Thai migrants. American Sociological Review, 70(5), 779-800. https://doi.org/10.1177/ 000312240507000503

Lahti, M. (2013). Cultural identity in everyday interactions at work: Highly skilled female Russian professionals in Finland. Nordic Journal of Working Life Studies, 3(4), 21-43. http://www.nordicwl.com/?p=1286

Levitt, P. (2001). The transnational villagers. University of California Press.

Liebkind, K., Mähönen, T. A. E., Varjonen, S. A., \& Jasinskaja-Lahti, I. (2016). Acculturation and identity. In D. L. Sam \& J. W. Berry (Eds.), Cambridge handbook of acculturation psychology (pp. 30-49). Cambridge University Press.

Lubbers, M., Molina, J. L., \& Mccarty, C. (2021). How do migrants' processes of social embedding unfold over time? Global Networks, 21(3), 529-550. https:// doi.org/10.1111/glob.12297

Mikkola, L., Suutalab, E., \& Parviainen, H. (2018). Social support in the workplace for physicians in specialization training. Medical Education Online, 23(1). https://doi.org/10.1080/10872981.2018.1435114

Morrison, R. L., \& Cooper-Thomas, H. D. (2016). Friendship among coworkers. In M. Hojjat \& A. Moyer (Eds.), The psychology of friendship (pp. 123-140). Oxford University Press. https://doi.org/10.1093/ acprof:oso/9780190222024.003.0008

Pahl, R. (2000). On friendship. Polity Press.

Podolny, J., \& Baron, J. (1997). Resources and relationships: Social networks and mobility in the workplace. American Sociological Review, 62(5), 673-693. https://doi.org/10.2307/2657354

Povrzanović-Frykman, M., \& Mozetič, K. (2020). The importance of friends: Social life challenges for foreign physicians in southern Sweden. Community, Work \& Family, 23(4), 385-400. https://doi.org/ 10.1080/13668803.2019.1599323 
Ryan, L. (2011). Migrants' social networks and weak ties: Accessing resources and constructing relationships post-migration. The Sociological Review, 59(4), 707-724. https://doi.org/10.1111/j.1467-954X. 2011.02030.x

Ryan, L. (2015). Friendship-making: Exploring network formations through the narratives of Irish highly qualified migrants in Britain. Journal of Ethnic and Migration Studies, 41(10),1664-1683. https://doi.org/ 10.1080/1369183X.2015.1015409

Ryan, L. (2018). Differentiated embedding: Polish migrants in London negotiating belonging over time. Journal of Ethnic and Migration Studies, 44(2), 233-251. https://doi.org/10.1080/1369183X.2017. 1341710

Ryan, L., \& Mulholland, J. (2014). French connections: The networking strategies of French highly skilled migrants in London. Global Networks, 14(2), 148-166. https://doi.org/10.1111/glob.12038

Ryan, L., \& Mulholland, J. (2015). Embedding in motion: Analysing relational, spatial and temporal dynamics among highly skilled migrants. In L. Ryan, U. Erel, \& A. D’Angelo (Eds.), Migrant capital: Networks, identities, strategies (pp. 135-53). Palgrave Macmillan.

van Riemsdijk, M., Basford, S., \& Burnham, A. (2016). Socio-cultural incorporation of skilled migrants at work: Employer and migrant perspectives. International Migration, 54(3), 20-34. https://doi.org/ 10.1111/imig.12221

van Riemsdijk, M., \& Wang, Q. (2017). Rethinking international skilled Migration. Routledge.
Varjonen, S., Arnold, L., \& Jaskinskaja-Lahti, I. (2013). "We're Finns here, and Russians there": A longitudinal study on ethnic identity construction in the context of ethnic migration. Discourse \& Society, 24(1), 110-134. https://doi.org/10.1177/095792651 2463632

Vihavainen, T. (2013). Ryssäviha, Venäjan-pelon historia [Russophobia. A history of the fear of Russia]. Minerva.

Wimmer, A., \& Glick Schiller, N. (2002). Methodological nationalism and beyond: Nation-state building, migration and the social sciences. Global Networks, 2(4), 301-334. https://doi.org/10.1111/1471-0374. 00043

Wittel, A. (2001). Toward a network sociality. Theory, Culture \& Society, 18(6), 51-76. https://doi.org/ $10.1177 / 026327601018006003$

Wrzus, C., Hänel, M., Wagner, J., \& Neyer, F. J. (2013). Social network changes and life events across the life span: A meta-analysis. Psychological Bulletin, 139(1), 53-80. https://doi.org/10.1037/a0028601

Yakubovich, V., \& Burg, R. (2019). Friendship by assignment? From formal interdependence to informal relations in organizations. Human Relations, 72(6), 1013-1038. https://doi.org/10.1177/ 0018726718789479

Yeasmin, N. (2012). Life as an immigrant in Rovaniemi, Finland. In M. Tennberg (Ed.), Politics of development in the Barents region (pp. 340-361). Lapland University Press.

\section{About the Author}

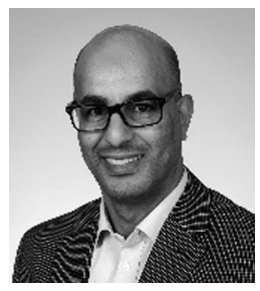

Driss Habti is a postdoctoral researcher in sociology at the University of Eastern Finland. His research interests surround international highly skilled migration, ethnicity and social inclusion, cultural diversity, sociology of work, and career mobility of migrant academics. His interests also include Bourdieu's sociological theory, and qualitative life course methods. He teaches sociology of migration, and the intersections of globalization, migration and cultural diversity. Habti published edited volumes and peer-reviewed scholarly papers ranging across the aforementioned fields. 